\title{
Program and School Characteristics Related to Teacher Participation in School Health Promotion
}

\author{
Nina Grieg Viig ${ }^{*}, 1$, Hege E. Tjomsland ${ }^{2}$ and Bente Wold ${ }^{2}$ \\ ${ }^{I}$ Bergen University College, Faculty of Education / Research Centre for Health Promotion, Faculty of Psychology, \\ University of Bergen, Norway \\ ${ }^{2}$ Research Centre for Health Promotion, Faculty of Psychology, University of Bergen, Norway
}

\begin{abstract}
The aim of this study was to investigate conditions related to teacher participation in the planning and implementation of the Norwegian part of the European Network of Health Promoting Schools. One hundred and four teachers responded to the questionnaire at baseline and at three year follow-up. Teachers' personal interest and regard for the program aim were the main predictors of their self-reported participation in the program. Conditions perceived as enabling or hindering program implementation, as well as baseline characteristics of school culture and professional discretion were to a high extent related to participation in the program (Multiple $\mathrm{R}^{2}=.52$ ). Health promotion aiming at increasing the students' wellbeing and improving the school environment seemed to have been well received by teachers, and enabled their participation in the program. The findings imply that programs encouraging networking are likely to be successful in engaging teachers, and that such networking yields ample opportunities for professional learning.
\end{abstract}

Keywords: Health promoting school, teacher participation, network, professional learning, professional discretion, supportive culture.

Teacher participation is considered an important precondition for school development processes. However, there is no general "recipe" for how to facilitate teachers" participation in such processes, just as there is no "recipe" for how to facilitate school development processes in general $[1,2]$. This study investigates factors enabling or hindering teacher participation in the planning and implementation of the Norwegian part of the European Network of Health Promoting Schools.

The 'Health Promoting School' (HPS) is a relatively recent concept, but the notion that the school setting can have a wide and varied role in meeting and influencing the health of young people and future adults is not new [3-5]. A HPS initiative is grounded in a holistic view of health, with the target being not just individual lifestyle, but the wider organisational and socio-environmental context of the whole school community [6-8]. Consequently, the development of a HPS involves a move from practices that rely mainly on classroom-based health education models to a more comprehensive, integrated construct of health promotion [6].

\section{THE NORWEGIAN NETWORK OF HEALTH PROMOTING SCHOOLS}

The Norwegian Network of Health Promoting Schools is part of the European Network of Health Promoting Schools (ENHPS). The ENHPS was established in 1992 by the WHO, the European Commission, and the Council of Europe [9]. Forty-three European countries participated in the network in 2009; the network is currently run as the Schools for Health in Europe (SHE) aiming to be the European

*Address correspondence to this author at the Bergen University College, Faculty of Education, Norway. Tel: +47 55585839.

E-mail: Nina.Grieg.Viig@hib.no platform for school health promotion working at the school, national, and international level (http://www.schoolsfor health.eu/).

The HPS program differs from other health-promoting and preventive measures in schools by being an overall policy program presupposing and facilitating changes in schools' traditional methodology and policy. The uniqueness of the HPS program lies in the way it focuses on including the whole school community in developing and implementing health promoting interventions $[10,11]$.

The ENHPS initially developed 12 criteria for a HPS [12]. Included in these criteria were guidelines about health enhancing physical and psychosocial environments, changes in curriculum in terms of content and teaching practice, as well as changes in the schools' health related policies. Moreover, these criteria also emphasized a HPS' obligation to establish good liaisons with other schools, parents, outside agencies, and the wider community on a range of health promotion initiatives.

HPS have developed across Europe taking the diversity in culture and national settings into consideration. Rasmussen [13] notes that there was a general agreement within the ENHPS on the aims of HPS. She further argues that the ENHPS contributed to the development of HPS through building consensus and collaboration at the European level, initiating the agenda for health promotion within the educational sector, and inspiring teachers to find new teaching methods. There seems to be an agreement that the HPS is a promising framework for health promotion practice in school, although Stewart-Brown [14] underscore that there is no evidence demonstrating that the HPS in its entirety is more effective in the promotion of health in school than other approaches. 
The focus of the HPS program has been adapted to national and local needs in each country. In Scotland, a focus on "healthy eating" was employed [15], while focus points for school health promotion in the Netherlands were sports and physical exercise, social skills development and personal care [16].

In Norway, all the schools chose improved student wellbeing and learning environment as major aims of their program, with mottos such as "'a good place to be is a good place to learn". The Norwegian network was established in 1993. Ten schools geographically spread in all parts of the country participated in the first (pilot) phase of the program. These schools spent 10 years planning, implementing, and evaluating their HPS effort [10]. The schools in the network were challenged to develop projects based on the schools' own needs and priorities, and they were encouraged to acknowledge already existing prevention and health promotion activities that had been running in the schools before they became members in the network. Within several of the participating schools, these existing programs and activities were points of departure when starting the HPS program. The Norwegian HPS program was implemented as a combination of a top-down and a bottom-up strategy, employing a whole-school approach, with participation of the stakeholders as a condition for the development and implementation processes.

The schools were expected to run the program without additional resources. However, as the evaluation of the program was predicted to significantly increase the amount of work for the program leader in each school, they were given a reduction of two hours weekly in their teaching duties in the period from 1995 to 1998. In addition, the schools were given a budget of NOK 5,000 (approximately $550 €$ ) to get started in 1994 . During the program period, there were no regular courses about health promotion or HPS for the teachers. Seminars were arranged for the school program managers and principals who met regularly once a year. The schools were provided with relevant educational materials and literature about health promotion work among children and adolescents, but the responsibility for training of teachers was given to each school. The HPS program managers were appointed from the staff in 4 of the schools; in the remaining 6 schools, the principal or one other member of the school's leadership group acted as the program manager.

As is the case with several of the countries participating in ENHPS, there is currently no national network of health promoting schools in Norway. However, the principles promoted through the network have been taken forward as a model for new school-based health-related national programs, such as "Healthy eating and daily physical activity in schools". Further, the importance of promoting and using the principles of HPS for such programs is also written into the most recent White Paper from the Ministry of Health, and systematically used in the education sector.

\section{FACTORS ENABLING TEACHER PARTICIPATION IN HEALTH PROMOTION}

Recently, there has been a recognition within health promotion literature to stress the importance of management of change and to build up appropriate strategies for implementing health promotion programs in different settings [4]. There are also clear recommendations for a high degree of participation of the stakeholders in the development process [4, 17-19]. Similarly, within school development, Fink and Stoll [20] suggest that change occurs best with "a 'top-down, bottom-up' approach in which the larger system provided direction and support and the actual change process was left to schools through school-based decision making and school development planning" (p. 305). Fink and Stoll also put emphasis on school-selected priorities for development, and they highlight the importance of teacher participation in change efforts, and their ownership of the process, as fundamental principles of school development processes. In a review of evaluation studies of HPS, Mukoma and Flisher [21] find a general agreement that the teachers are keys to the development, implementation and evaluation processes, and ultimately to the success of the interventions.

An assumption in most organisational change research is that it is not sufficient to change only individuals within a system. Any improvement needs to be maintained through appropriate changes in the supporting appraisal, compensation, training, staffing, task and communications subsystems [22]. Hargreaves and his colleagues [23] identify five major areas that significantly influence teachers' attempts to incorporate changes into their daily routines, factors that the authors find are crucial to support and sustain changes in the teachers' work: 1) school structures; 2) teacher culture; 3) professional learning; 4) professional discretion; and 5) school leadership.

School structures, such as school architecture, timetable, length of lessons, allocated time for teamwork and teacher collaboration can seriously hinder (or facilitate) efforts for making changes $[1,3,18,23]$. In a qualitative study among 12 teachers from two of the schools in the Norwegian HPS, such school structures were listed as prerequisites for teacher participation in the development and implementation processes of the program [11]. Likewise, a Dutch survey among 180 primary school teachers indicated that a majority of the teachers considered lack of time as an important barrier for their engagement in school health promotion, while lack of financial resources did not seem to be perceived as important [16].

A school's culture is one of its most enduring aspects, and it is deeply rooted in the people working there. Imsen [24] defines school culture as a school's prevailing fundamental views, such as norms, values, beliefs, as well as history and traditions, placed at the school's organisational level. The school culture influences the teacher culture, and strong collaborative, supportive cultures or professional communities in teaching are powerfully linked to, and can provide, essential support for implementing effective and sustained changes $[1,23,25,26]$. A multiple case study with four schools in the Scottish Network of Health Promoting Schools identified "a special school health day" as the most commonly described positive event related to health promotion in the schools [15]. This event had been planned and implemented collaboratively by the members of the school community and outside representatives. Teachers reported that they gained experience as health-promoting teachers in an authentic setting, and that their learning, 
thinking and knowing arose through collaboration with others. According to Inchley et al. [15], teachers feel themselves professionally responsible for health promotion when they are involved in a process of mutual activity to share and construct new knowledge and skills in partnership with health care professionals. Findings from the Finnish part of the ENHPS suggest that there was a shift from mostly teacher-centred teaching methods to more collaborative teaching and learning methods during the project period. More collaboration was seen between staff and outside representatives, and the teachers perceived that the atmosphere in the classroom and in the school community developed favourably $[27,28]$.

A 14 year follow-up study of seven of the schools in the Norwegian Network of HPS, suggested that the school leaders established collaborative cultures for health promotion by building shared visions and aspirations with their staff [29]. They felt that health promotion should be part of everyday practice in schools, and statements such as "it is in the walls" and "under the teachers' skin" indicate that health promotion practices were sustained after 14 years. These findings support the notion that the school development program needs to be a common commitment in the school organisation, and a supportive culture can facilitate a good climate for development discussions and intellectual confrontations among the teachers [30]. Social support with regard to the amount of helpful social interaction with managers and colleagues is vital for teachers' professional learning in new activities [31], which thereby increases the likelihood of teacher participation in HPS.

Professional learning is essential for successful implementation and sustainability of program changes in school [23]. Green and Kreuter [18, p.201] state that "Training and supervision of personnel provide the best assurance of implementation". Parsons and colleagues [32] found that schools that were successful in disseminating ideas and gaining staff commitment for the HPS emphasised staff development and training. This finding was supported by St Leger [33] in his evaluation of Australian HPS and Denman's [3] review of research and practice of HPS in England.

Hargreaves and Fink [34] also suggest that professional learning networks may contribute to sustainable improvements because they generate excitement in teachers through interaction with colleagues across schools. Network based initiatives build on the idea that teachers learn best when they share ideas, collaborate about planning and provide feedback to others' ideas and experiences [34].

Professional discretion implies that teachers are able to adapt the health promotion program to their own way of teaching, in particular to invest their personal interests and enjoyment into their participation in health promotion. Personal interests include the attitudes and beliefs that teachers hold towards health promotion. A survey of the teachers at the initiation of the Norwegian HPS suggested that most teachers were interested in working with health and wellbeing in school [35]. Moreover, teachers' attitudes and expectations regarding the outcome of the program at baseline were highly associated with their participation in HPS at three year follow-up. Studies from Finland, Australia and Greece also suggest that teachers are positive to health education and health promotion $[28,36,37]$, indicating that teachers may find it easy to incorporate the aims and strategies of these types of school development programs into their teaching. However, experiences from the Scottish Network of Health Promoting Schools suggest that although teachers were positive at the initiation of the program, staff must be granted time to rethink their practice and to embrace the HPS approach [15].

Several of the countries in the ENHPS have conceptualized a democratic approach to health education and the HPS [38, 39]. Here, the focus is on educational rather than health outcomes and the overall aim of democratic health education and the HPS is development of students' action competence to enable responsible and critical participation in health matters that concern the students [40]. HPS aimed at improving student development and the learning environment contain elements of pedagogical caring as proposed by Wentzel [41]: teachers demonstrating democratic interaction styles, developing expectations for student behaviour in light of individual differences, modelling a "caring" attitude toward their own work, and providing constructive feedback. Pedagogical caring may constitute an important element in the teachers' professional discretion.

Thus, successful changes in schools depend on teachers being accorded enough time, space, training and professional discretion. Such assets are impossible without effective school leadership. School leaders are "vital agents for creating the conditions in which a school reform can succeed" [23, p. 175]. A conscious and reflective school leadership is a precondition for a successful program $[1,3$, $30,42-44]$. The program leadership or the role of the change agent is also important for gaining support of a critical mass of staff [4]. Leithwood, Harris, and Hopkins [45] suggest that leadership is about improving the performance of teachers, which is again a function of the teachers' beliefs, values, motivations, skills, and knowledge, and their working conditions. If principals motivate teachers so that they have the "will" and the "capacity" to carry out the recommended changes, school reform and change are more likely.

In their evaluation of Second Step, a school-based social skills development program, Larsen and Samdal [46] found that key features of successful implementation and sustainability relates to a strong, continued and systematic focus by principals on leadership as well as specific management strategies. Laurence et al. [47] point to effective leadership and dedicated resourcing at the school level as key factors of success in Australian HPS schools. Here leadership was essential in terms of establishing local partnerships with resource people who coordinated and guided the program and increased the capacity of the teaching staff to be engaged. Several other studies also point to the importance of leadership executed by the principal as vital to sustain school improvement initiatives [48-52].

\section{RESEARCH QUESTIONS}

The above review of the literature suggest that teachers are more likely to participate in school health promotion if they are accorded enough time, space, training and 
professional discretion, as well as effective leadership. The characteristics of the program may determine the extent to which these conditions influence teacher participation. With this background, the following research questions are examined:

1. To what extent do teachers perceive that characteristics of the aims and implementation of the HPS program, school structure, teacher culture, professional learning and discretion, and school leadership enable their participation in the program?

2. To what extent are these teacher perceptions related to their participation in the program?

\section{METHODOLOGY}

\section{Sample}

The present study is part of an overall evaluation study of the Norwegian HPS. The Ministry of Education invited all (approximately 3000) primary and secondary schools in the country to participate in the Norwegian network. Of a total of 40 applications, 10 pilot schools were selected, representing a strategic sample in terms of geographical localisation, size and grade levels [10]. The classes were spread from $1^{\text {st }}$ to $9^{\text {th }}\left(10^{\text {th }}\right)$ grade ${ }^{1}$ with an equal number of males and females.

One of the schools was eliminated from the survey data due to a change in school zone and a large turnover of teachers at the school. At baseline in 1994, a total of 200 teachers and principals worked in the nine schools included in this study, and 191 of them (96\%) responded to the questionnaire. The inclusion criteria for the present study were that teachers and principals had to be available for data collection at baseline and at the three-year follow-up. According to school employment records, about 30 of the 200 teachers were employed on a part-time basis on shortterm contracts, and were therefore not eligible for analysis of longitudinal data. Another 30 teachers were not eligible because of sick leave, maternity leave, educational leave or new employment or retirement during the study period. Consequently, it was estimated that a maximum of 140 teachers could participate in the longitudinal study from baseline to three-year follow-up; 104 of these (75\%) responded at both points in time. Fifty-two of these teachers were females and 51 were males (one teacher had a missing value on the sex variable). The teachers were from 23 to 68 years old, with the average age being 45 years. Twenty-four teachers were employed in elementary schools, 56 teachers worked in junior high schools and 24 were employed in combined elementary and junior high schools. The data collection was approved by The Norwegian Data Inspectorate.

\section{The Questionnaire}

Participation in the HPS program at three-year followup. Three questions with 22 items in total were used to measure teachers' participation in the planning and implementation of the program.

\footnotetext{
${ }^{1}$ Note: In 1997, a new National Curriculum was introduced in Norway, including the 6-year olds as a new group into school. As a consequence, since 1997 , the primary schools incorporate $1^{\text {st }}-7^{\text {th }}$ grade and the secondary schools incorporate $8^{\text {th }}-10^{\text {th }}$ grade.
}

1. To what extent did you participate in the planning of the program at different levels? A list of six levels was provided: school class; teacher team; grade level; school; staff; local community. The five response categories were from (the parentheses show the recoded values used in the analysis): "to a large degree" (4) to " not at all" (0).

2. To what extent did you participate in the implementation of the program at different levels? The same list of 6 levels and response categories was provided.

3. To what extent have you been working on the following areas of the HPS program? A list of nine items was provided: a) alcohol, drugs and tobacco prevention, b) diet, c) physical activities, d) the outdoor physical environment, e) the indoor physical environment, f) the psychosocial environment among students, g) the psychosocial environment among staff, h) preparing cross-curricular plans for health and health promotion, and i) networking at the national level. The four response categories were from "to a large degree" (3) to "not at all (0).

In the analyses, a formative index was constructed as a sum score of the 22 items. The use of a formative index was based on the recommendations of Diamantopoulus and Winklhofer [53] suggesting that when constructs are conceived as explanatory combinations of indicators that are determined by a combination of variables, their indicators should be formative.

\section{Baseline Measures}

The baseline measures of school culture as indicated by items on pedagogical caring correspond to those applied by Wentzel [41] when measuring students' perceptions of pedagogical caring, while the other items were adapted from Olweus [see 54].

Teacher culture. Three items were combined into a sumscore (Cronbach's alpha .77): There is a good collaboration among the teachers; The teachers usually plan their teaching together; We use teamwork frequently. The response categories were the same as above.

Professional discretion. Three items were combined into a sumscore measuring pedagogical caring at baseline (Cronbach's alpha .78): I care about each student; I am friendly and nice to the students; I often praise the class, with five response categories from "agree completely" (4) to " do not agree at all (0).

Three items were combined into a sumscore measuring Job satisfaction at baseline (Cronbach's alpha .71): I like this school; I like being a teacher with four response categories from "very much (3) to "not at all" (0); and I like to work at this school with six response categories from "very much" (5) to "not at all" (0).

School Leadership. Three items were combined into a sumscore (Cronbach's alpha .87): The school leadership appreciate that the teachers come up with suggestions for changes; There is a good collaboration between the school leadership and the teachers; There is agreement on how the school should be run. The six response categories were from "agree completely" (5) to "do not agree at all" (0). 


\section{Measures at Three Year Follow-Up}

Two questions on program content and implementation with a number of items were derived from in-depth analyses of qualitative interview data from teachers in two of the Norwegian network schools, performed by the main author of this study [11].

1. How important do you think these factors have been to facilitate your participation in the HPS program at your school? A list of seven items was provided (see Table 2), the response categories ranging from very important (4) to not important (0).

2. What factors do you think have hindered your participation in the HPS program at your school? A list of nine items was provided (see Table 2), the five response categories ranging from very important (4) to not important (0).

Based on content validity with regard to the 5 factors proposed by Hargreaves and colleagues [23], inspection of intercorrelations and exploratory factor analysis, four sumscores were created; Program Resources reflecting school structures (Cronbach's alpha .78), Program Staff Focus reflecting teacher culture (Cronbach's alpha .78), Program Aims and Policy reflecting opportunities for teacher collaboration and professional learning (Cronbach's alpha .77); and Program Management reflecting school leadership (Cronbach's alpha .87). The item concerning Personal Interest was kept as a single item, expected to reflect professional discretion.

\section{Data Collection}

Within a longitudinal design, surveys were conducted annually in November from 1994 to 1998 through self-report questionnaires, administered among all the teachers. The teachers were given time within their working hours to fill in the questionnaires, and a procedure ensuring confidentiality was employed. Data from two time-points, 1994 and 1997, are analysed in this study. Data from the 1998 survey could not be used for this study, because it did not include the variables needed to address the research questions in the present study.

\section{Data Analysis}

All analyses were performed using SPSS for Windows, version 15.0 and included descriptive analyses, Pearson correlations, and linear multiple regression analysis.

\section{Reliability and Validity}

The internal consistency and reliability for the reflective indices were satisfactory, as indicated by Cronbach's alpha's ranging from .71 to .87 . The validity of the questions about facilitating and hindering factors was found to be satisfactory based on feedback from discussions between teachers, research team members and experts in school health promotion on the quality of the questionnaire.

The sample may not be representative of Norwegian teachers in general. The teachers in this study may have been more positive to school health promotion than other teachers because they worked in schools that applied for enrolment in the ENHPS. Another selection bias is that teachers (among them the program managers at each school and the principals) who were eligible for a longitudinal study might have been among the most positive teachers in the network since less positive teachers might have dropped out of the survey. However, based on the inclusion criteria and the response rates of teachers satisfying these criteria, it is likely that the respondents were representative of permanent teacher staff involved in the HPS.

\section{RESULTS}

The descriptive statistics of the formative index and the reflective indices by gender are presented in Table $\mathbf{1}$. The most notable finding is that no statistically significant differences between males and females were observed. Thus, gender was not included in the subsequent analyses.

As suggested by Table 2, more than half of the teachers indicated that the items reflecting opportunities for professional learning through the program, with its focus on a safe and good environment for the students, and program support from the leadership, were very important or important reasons enabling them to participate in the

Table 1. Descriptive Statistics of Sumscores of Teacher Participation in the Norwegian HPS Program, Perceived Characteristics of Work Environment at Baseline and Conditions Perceived to Enable Participation in the Program by Gender

\begin{tabular}{|c|c|c|c|c|c|c|c|c|}
\hline & \multirow{2}{*}{ Range } & \multicolumn{3}{|c|}{ Male } & \multicolumn{3}{|c|}{ Female } & \multirow{2}{*}{$\begin{array}{c}\text { Gender } \\
\text { Diff. }\end{array}$} \\
\hline & & Mean & SD & $\mathbf{N}$ & Mean & SD & $\mathbf{N}$ & \\
\hline Participation at 3 year follow.up & $0-78$ & 28.4 & 14.46 & 40 & 30.5 & 16.62 & 40 & NS \\
\hline Baseline Leader Collaboration & $0-15$ & 8.3 & 3.51 & 49 & $8-0$ & 4.18 & 49 & NS \\
\hline Baseline Colleague Collaboration & $0-15$ & 8.4 & 3.02 & 50 & 8.3 & 3.02 & 48 & NS \\
\hline Baseline Pedagogical Caring & $0-12$ & 9.3 & 1.63 & 49 & 9.6 & 1.47 & 49 & NS \\
\hline Baseline Job Satisfaction & $0-11$ & 8.6 & 1.76 & 50 & 9.0 & 1.36 & 47 & NS \\
\hline Program Aims and Policy & $0-16$ & 8.1 & 3.30 & 47 & 8.5 & 3.30 & 43 & NS \\
\hline Program Leadership & $0-8$ & 4.8 & 2.18 & 44 & 5.0 & 2.26 & 42 & NS \\
\hline Program Resources & $0-20$ & 11.0 & 3.91 & 48 & 11.7 & 3.86 & 43 & NS \\
\hline Program Staff Focus & $0-12$ & 6.3 & 2.93 & 48 & 6.6 & 2.97 & 44 & NS \\
\hline Program interest & $0-4$ & 2.3 & 1.09 & 49 & 2.4 & 1.15 & 45 & NS \\
\hline
\end{tabular}


Table 2. Percent Teachers Responding "Very Important or Important" to whether Conditions Enabled or Hindered their Participation in the Norwegian HPS Program, and Pearson Correlations (r) Between Each Condition and Self-Reported Participation in the Program

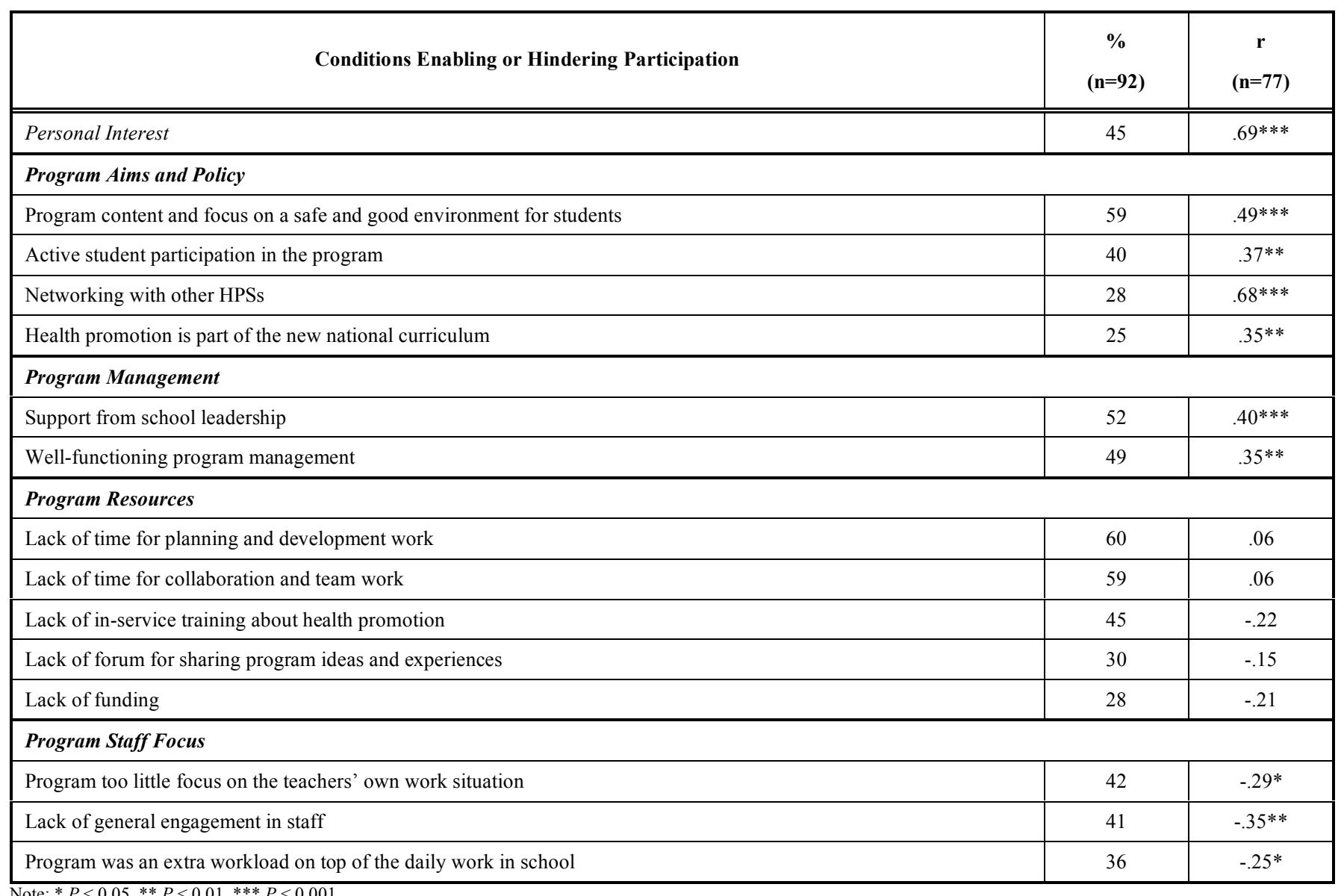

Note: $* P<0.05, * * P<0.01, * * * P<0.001$.

Norwegian HPS program. Among the conditions perceived to hinder participation, structural factors such as lack of program resources in terms of lack of time for planning and collaboration were also reported by more than half of the teachers.

Items reflecting professional learning and discretion, such as personal interest and perceiving networking with other schools as important enabling conditions had the highest correlations with self-reported program participation, while lack of program resources was not statistically significantly associated with program participation. Factors related to teacher culture such as a perceived lack of staff focus in the program was significantly and moderately associated with less program participation.

Teachers' perceptions of the program aims and policy as important conditions enabling their participation correlated highly with their perceptions of program management (.73) and their personal interest in the program as important enabling conditions (.73) (Table 3). Perceiving good collaboration with the school leadership at baseline was significantly related to almost all other measures, especially to teacher culture as measured by collaboration with other teachers and job satisfaction at baseline, but also to conditions perceived to enable their participation in the program at three year follow-up (Table 3). Structural conditions related to lack of resources perceived to hinder their participation at three year follow-up was the only variable not statistically significantly related to collaboration with leaders at baseline.

Table 4 shows the results of the multiple regression analyses. The first step included indicators of baseline work environment only, explaining $21 \%$ of the variance in participation. The strongest predictor was perceived collaboration with the school leadership. In the next step, characteristics of the program content and implementation were added, significantly increasing the explained variance to $46 \%\left(\mathrm{R}^{2}\right.$ change from Model 1 to 2 was $.27, \mathrm{~F}=9.28$, $\mathrm{df}=4,65, \mathrm{p}<.001)$. Professional learning as reflected by the teachers' perceptions of the importance of program aims were the strongest predictor of participation at this step, while structural conditions reflected by perceived lack of program resources was the only other significant predictor. At the final step, an indicator of professional discretion, namely personal interest in the program, was added, significantly increasing the explained variance to $52 \%\left(\mathrm{R}^{2}\right.$ change from Model 2 to Model 3 was $.06, F=8,79$, $\mathrm{df}=1,64$, $\mathrm{p}<.01)$. Perception of program aims being important continued to be a significant predictor, although the standardized beta decreased considerably. 
Table 3. Correlations (Pearson's r) between Baseline Measures of Perceived Collaboration with Other Teachers and School Leadership, Job Satisfaction and Pedagogical Caring, and Perceived Characteristics of the Content and Implementation of the Norwegian HPS Program at 3 Year Follow-Up

\begin{tabular}{|c|c|c|c|c|c|c|c|c|}
\hline & 2 & 3 & 4 & 5 & 6 & 7 & 8 & 9 \\
\hline \multicolumn{9}{|l|}{ Baseline } \\
\hline 1. Teacher Collaboration & $.27 * *$ & .18 & $.42 * * *$ & -.12 & .11 & $.26^{*}$ & $.27 *$ & $.33 * *$ \\
\hline 2. Job Satisfaction & & $.32 * *$ & $.50 * * *$ & -.13 & -.02 & $.27 *$ & $.31 * *$ & $.25^{*}$ \\
\hline 3. Pedagogical Caring & & & .13 & -.07 & .19 & .15 & $.29 * *$ & $.29 * *$ \\
\hline 4. Leader Collaboration & & & & $-.25 *$ & -.10 & $.38 * * *$ & $.40 * * *$ & $.27 * *$ \\
\hline \multicolumn{9}{|l|}{ Program Characteristics } \\
\hline 5. Staff Focus & & & & & $.38^{*}$ & -.24 & $-.24 *$ & $-.25 *$ \\
\hline 6. Resources & & & & & & .20 & $.24 *$ & .09 \\
\hline 7. Management & & & & & & & $.73 * * *$ & $.52 * * *$ \\
\hline 8. Aims and Policy & & & & & & & & $.73 * * *$ \\
\hline 9. Program Interest & & & & & & & & 1 \\
\hline
\end{tabular}

\section{DISCUSSION}

This study indicated that teachers in the Norwegian Network of Health Promoting Schools to a large extent perceived that their participation in the program were enabled by its characteristics, namely a focus on a good and safe environment for the students, and program support from the leadership. Lack of time for working with the program was perceived as an important hindering condition, reported by more than half of the teachers, while lack of funding seem to be regarded as less important.

Perceptions of the enabling and hindering conditions related to the program, such as opportunities for professional learning and discretion, as well as baseline characteristics of school leadership and professional discretion were to a very high extent related to teacher participation in the planning and implementation of the Norwegian HPS, as evidenced by a Multiple $\mathrm{R}^{2}$ of .52 .

\section{School Structures}

As suggested by Green and Kreuter [18] and Hargreaves and colleagues [23], allocating time and funding is a fundamental prerequisite for successful implementation of a program. Sixty $\%$ of the teachers in this study also rated lack of time for program planning and collaboration as the most important condition hindering their participation in the program. However, only $28 \%$ of the teachers responded that they perceived lack of funding to be an impediment to the accomplishment of the program. This finding was surprising, as the Norwegian HPS did not offer funding of the activities in each school. Moreover, teachers' opinions about lack of time did not seem to be related to their self-reported participation in the program, nor was lack of funding. These findings are consistent with those of a Dutch study in which a majority of the teachers rated lack of time as an important barrier to engage in health promotion [16]. Lack of funding was apparently not perceived as an obstacle by the Dutch teachers, and neither lack of time nor funding was related to engagement in health promotion.
Of all the conditions included in the present study, finding lack of such program resources important was actually the only ones not significantly correlated with personal interest in the program and self-reported participation. This finding should probably not be interpreted as claiming that time and other resources within the school structure are not important. It is likely that teachers deem lack of time and funding as important barriers regardless of how much they are interested and involved in a program, thus explaining the low correlation. Another explanation can be that personal interest in the program compensated for lack of resources.

\section{Teacher Culture and Professional Learning}

Among the indicators of program aims and policy, networking with other HPS was most closely associated with teacher participation. Being involved in a network may have contributed to new types of professional collaboration, and learning from the experiences and activities of other schools (and teachers) in the network. A previous in-depth interview study at three- year follow-up among 12 of the teachers in the HPS did in fact indicate such professional learning [11]. The teachers highlighted the positive experiences they had through various kinds of networking in the program-both within their own school and with the other HPS in Norway and other countries [11]. For example, some of the teachers commented that being part of the HPS program triggered more teamwork (with colleagues) in planning crosscurricular health programs.

Other illustrations of the significance of networking can be found in the national newsletters in the Norwegian Network. A school program manager reported the following from a visit to Hungarian HPS: "In both schools we attended classes in music, arts and drama that was simply impressive. Hungary has a long tradition of cultural activities and tuition for children from the early years of their lives. We've got a lot to learn from them!" (Newsletter in 1996). In the 1997 Newsletter the program manager from another school reported that "It's fun and interesting, and gives an opportunity to get an impression of how school and everyday 
Table 4. Teacher Self-Reported Participation in the Norwegian HPS Program by Perceived Characteristics of Work Environment at Baseline and Conditions Perceived to Enable or Hinder Participation in the Program. Stepwise Regression Analysis $(\mathbf{n}=73)$

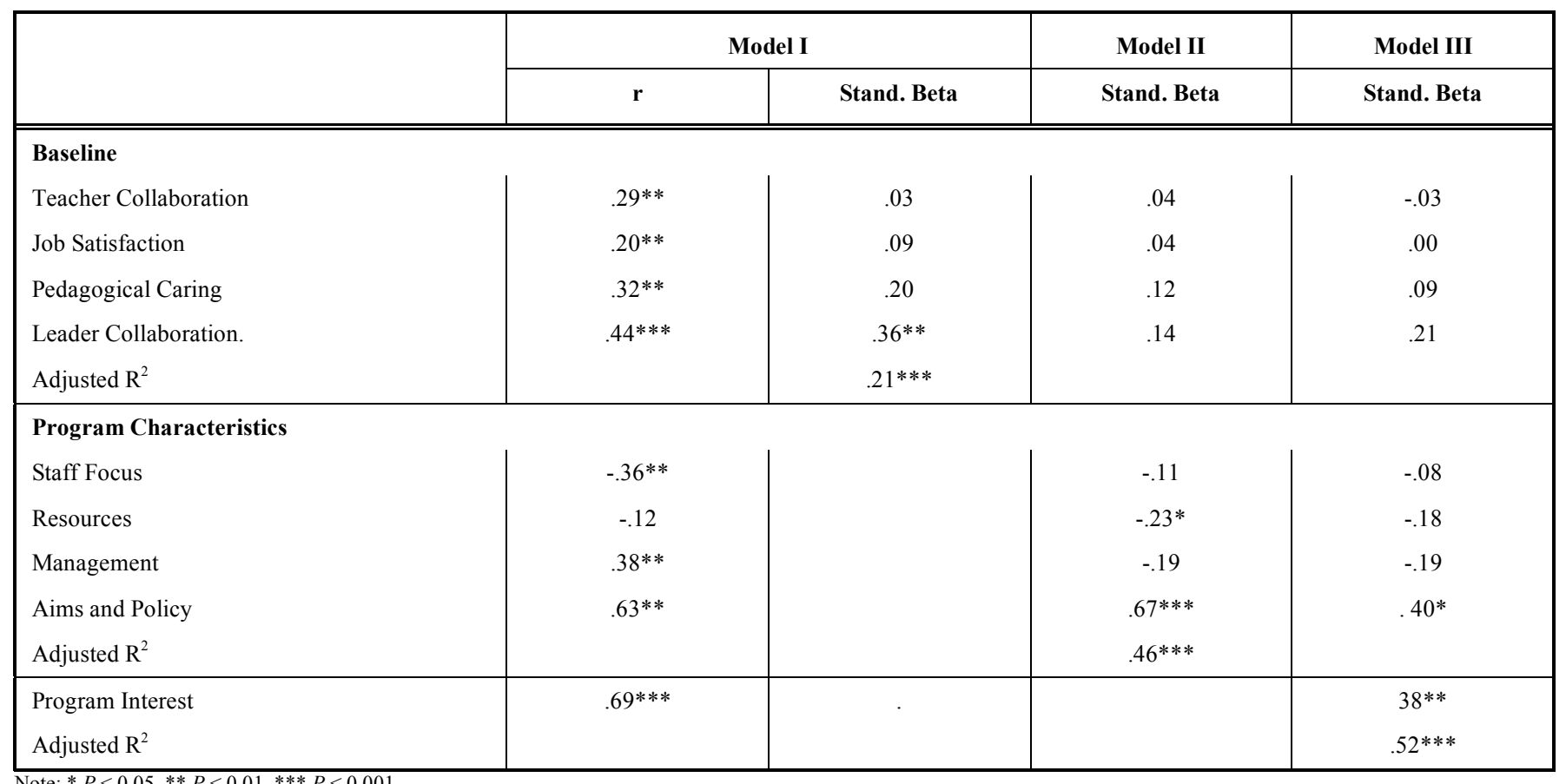

life is for students in other countries". These statements illustrate that networking was considered stimulating and inspiring. According to Rivett [55], the ENHPS demonstrates that bringing schools, teachers and principals together through the structure of a network strengthened the development of HPS by allowing for an exchange of ideas and experiences. The present findings support Rivett's claim that this was especially so in countries where more modern or interactive learning methods were being adopted, as was the case in Norway.

However, it is worthwhile to note that while networking was strongly related to teacher participation in the HPS program, only $28 \%$ of the teachers seemed to think that networking was important to them. This finding may indicate that teachers are not conscious about the opportunities that networking may offer for improved collaboration with their colleagues and for professional learning.

Professional learning is often accomplished through training and supervision. Most research literature within school change and development, as well as within the evaluation literature of the HPS, point to in-service training and development for teachers as important means to assure implementation [e.g. 18, 23, 56]. However, rather few, if any, of the teachers in the previously mentioned interview study [11] requested more education or training to acquire skills for running health promotion programs. The survey data reported here seem to confirm this finding, in that lack of in-service training was not found to be significantly associated with teacher participation in the program. It is possible that this finding can be explained by the fact that the schools were encouraged to develop their program based on prevention and health promotion activities they were undertaking before they became members of the network. Experiences from the Scottish network of HPS suggest that the chance of integrating and sustaining health promotion practice into the ongoing life of the school increased when the HPS was linked to existing practice and priorities [15]. The considerable degree of professional discretion embedded in the program may also have reduced the need for additional training, especially because the teachers may have felt confident about how to address the main aims of the program: students' wellbeing and improved learning environment.

\section{Professional Discretion}

The way the program was implemented seems to have fostered good conditions for professional discretion among the teachers, as the findings of this study indicated that teachers' personal interests seem to match well with the aims of the program. Moreover, according to the results of the multiple regression analysis the teachers' personal interests and regard for the program's aims were the main predictors of their self-reported participation in the program. These findings may imply that the teachers experienced that the program allowed for a high degree of professional discretion, as they seemed to believe that it was possible to invest their personal interests and enjoyment into the program. Thus, they probably adapted the health promoting program into their own way of teaching in the classroom and collaboration with colleagues. A Dutch study also suggests that teachers who were more involved in health promotion reported a higher level of confidence in their own skills to address health issues in class than other teachers [16].

Moreover, self-reported pedagogical caring at baseline was significantly related to program participation, as well as three year follow-up ratings of the importance of enabling 
factors such as personal interest in the program, and program aims. School health promotion aiming at improving students' wellbeing may therefore be attractive to teachers who exhibit caring attitudes toward their own work. These findings support the findings by Hargreaves and colleagues [23], suggesting that professional discretion is crucial to support and sustain changes in teachers' work.

\section{School and Program Leadership}

In line with previous studies [43, 46-48], this study suggests that effective leadership is vital to teacher support and participation in a school development program. Perceiving a good relationship with the school leadership at baseline was significantly associated with almost all other study variables, indicating that the school leadership may have been instrumental in building the capacity for the teachers to engage in the health promoting program. First, positive perceptions of the leadership at baseline were significantly associated with aspects of the teacher culture such as good collaboration and teamwork. Second, all baseline perceptions of the school work environment were significantly associated with teacher participation in the health promoting program, while only positive relationship to school leaders remained significant when all baseline indicators were regressed on teacher participation. These findings may imply that when school leaders are able to establish positive relationships with the staff, they are more likely to gain the commitment of the staff, and thus create conditions in which a program in health promotion can be successfully planned and implemented.

Moreover, teachers who reported a good relationship with the school leaders at baseline also tended to report at three year follow-up that program support from school leaders and a well functioning program management were important factors enabling their participation in the program. Thus, there seems to have been a consistency in the way the teachers perceived their leaders as supportive and competent throughout the program. This interpretation is supported by previous findings from a case study applying mixed methods in one of the schools, indicating that an extended physical activity practice was sustained in the case study school during the 10-year study period due to the ability of the principal and program manager to establish collaboration and commitment in the staff, and to ensure that their staff was given rewarding experiences and increased competence in the promotion of physical activity [29]. Another 14 year follow-up study of the sustainability of health promoting practices in seven of the schools in the Norwegian Network of HPS, also suggested that the leaders who had a strong, continued and systematic focus on health promotion increased the possibility for teachers to participate in the program [57].

The teachers seemed to regard leadership support of the HPS program and a good program management as important conditions enabling their participation, and these conditions were also significantly related to self-reported program participation. In addition, the teachers who placed emphasis on the importance of leadership support and management of the program as enabling conditions also rated program aims and policy as important. This finding may indicate that they felt that the school leader and program manager were attentive to their personal interests, and thereby may have built a sense of ownership to the health promotion program among the teachers. Again, this finding may be taken to support the assumption that leaders are instrumental in building the capacity for teachers to engage in health promotion.

\section{LIMITATIONS}

This study is based on teachers' self report, and the findings need to be interpreted accordingly. One could argue that teachers' reporting of participation in program activities may not be a good indicator of the actual, "objective" participation [58]. Having been involved in the program, the teachers may be biased to over-report their participation; and to report more positive perceptions of the school environment and conditions enabling them to participate due to social desirability. Despite the chance of self report bias, teachers' opinions of the conditions enabling their participation in the program are still valuable given that teachers act as gatekeepers for health promotion in the classroom [59].

The five factors suggested by Hargreaves and colleagues [23] constituted the theoretical basis for the grouping of variables in the present analyses, but was not available at the time of data collection. Therefore, the measures in the study should not be considered as direct operationalisation of the five factors, but rather as proximal measures reflecting these factors.

Given that the schools had applied for admission to the program and because perhaps only the most motivated teachers responded to the questionnaire, especially at followup, there is a chance of selection bias. Therefore, one should be careful in generalizing the findings from this study to teachers in general. However, the high response rate among the teachers who fulfilled the inclusion criteria, suggests that the findings are representative for the teachers who worked at these schools throughout the program period.

Another limitation is the relatively low number of respondents in the regression analysis, and the high correlations between some of the predictors, violating the assumption that the predictors must be linearly independent. The high intercorrelations between some of the predictors may explain why only two predictors remained significant in the final analyses, suggesting a substantial overlap across predictors in the explained variance in program participation.

\section{CONCLUSION}

This study of teacher participation in the Norwegian HPS program supports and complements previous evaluation studies emphasising the importance of professional discretion and structural and management arrangements for teacher participation in development and implementation processes [e.g. 3, 23, 33, 60]. The findings contribute insights into how enabling and hindering conditions are interrelated, as well as identifying conditions that may be particularly relevant to the implementation of health promotion programs in schools. It demonstrates that teachers' professional discretion may be respected by ensuring that the aims correspond to their interests and needs. 
The findings suggest that a health promoting program aiming at increasing students' wellbeing and improving the school environment is well received by teachers, and that such aims seem to enable them to participate in the program. This result indicates that the teachers perceived health promotion as meaningful and compatible with the educational mission, and that the match between the program's and teachers' aims is a critical condition related to change, as suggested by Schmidt and Datnow [61].

Moreover, the study findings imply that programs encouraging networking are likely to be successful in engaging teachers, and that such networking yields ample opportunities for improved teacher collaboration and professional learning. This aspect of the European Network of HPS may have been particularly attractive and stimulating for the principals and program managers at each school, possibly resulting in increased leadership support of the program.

Finally, the significant role of the school leadership was demonstrated in this study. A favourable school culture at baseline, as indicated by positive relationships between teachers and leaders, seems to form a solid basis for the development of a health promoting program, as well as providing the necessary support throughout the course of the program.

In conclusion, the study highlights how the five major factors crucial to support and sustain changes in teachers' work as identified by Hargreaves and colleagues [23] may have affected teacher participation in a health promoting program applying a whole-school approach. The study suggests that the teachers are likely to get involved in school health promotion when the HPS program offers opportunities for; i) sufficient time for collaboration in the program reflecting the importance of school and program structures; ii) developing better collaboration with their colleagues reflecting the importance of the teacher culture; iii) professional learning through networking; iv) professional discretion through participation and ownership in developing program aims; and v) experiencing that school and program leaders support their work with the program.

\section{IMPLICATIONS}

The findings of this study suggest a number of recommendations for development programs in schools. When introducing a school development program, it seems important to build on the already existing competences and interests of the teachers. Moreover, allowing for professional discretion seems to enable teachers to participate in health promotion, suggesting that teachers should take part in developing the aims of the program in their school.

The European Network of Health Promoting Schools has existed since the early 1990s. There has been a comprehensive amount of networking on the international level between the national coordinators in the network. This study suggests that one way of bringing school development programs forward could be through acknowledging the possibilities of professional learning offered through participation in networks. Thus, school development programs ought to advocate and facilitate for networking across schools among teachers, program managers and school leaders at the national as well as at the international level.

The policy implications of this study are similar to those of other studies from the ENHPS, as well as other school improvement programs. As suggested by Rasmussen [13], the first step from the piloting of a program to policy involves positive identification by decision makers. Here, in this case, this involves the acknowledgement of school health promotion by decision makers at different levels. The next steps involve building credibility and demonstrating relevance and feasibility; and finally incorporation into governmental policy. Furthermore, studies demonstrating that health promoting programs in school are effective in improving students' well being and school environment may convince the educational sector of the need to develop a policy on school health promotion.

\section{REFERENCES}

[1] Fullan MG. The new meaning of educational change, $3^{\text {rd }}$ ed. New York: Teachers College and Routledge Falmer 2001.

[2] West M, Ainscow M, Jacqui S. Sustaining improvement in schools in challenging circumstances: a study of successful practice. Sch Leadersh Manag 2005; 25(1): 77-93.

[3] Denman S. Health promoting schools in England - a way forward in development. J Public Health Med 1999; 21(2): 215-20.

[4] Tones K, Green J. Health promotion. Planning and strategies. London: Sage Publications 2004.

[5] Mittelmark MB, Kickbusch I, Rootman I, Scriven A, Tones K. Health promotion. In: Heggenhougen K, Quah S, Eds. International encyclopedia of public health, Oxford: Elsevier 2008; vol. 5.

[6] Deschesnes M, Martin C, Hill AJ. Comprehensive approaches to school health promotion: how to achieve broader implementation. Health Promot Int 2003; 18(4): 387-96.

[7] Inchley J, Currie C,Young I. Evaluating the health promoting school. Health Educ 2000; 100(5): 200-206.

[8] Samdal O. School health promotion. In: Heggenhougen K, Quah S, Eds. International encyclopedia of public health. San Diego: Academic Press 2008; pp. 653-61.

[9] Gray G, Young I, Barnekow V. Developing a health-promoting school. A practical resource for developing effective partnerships in school health, based on the experience of the European network of health promoting schools. Copenhagen: The WHO Regional Office for Europe, the European Commission and the Council of Europe 2006.

[10] Wold B. The European network of health promoting schools (ENHPS) in Norway: purpose, implementation and evaluation. In: Wold B, Samdal O, Eds. Health promotion among young people: the development of healthy schools environments. Dissemination of experiences from the European network of health promoting Schools (ENHPS). Bergen: University of Bergen, Research Centre for Health Promotion 1999; HEMIL Report Series No. 7.

[11] Viig NG, Wold B. Facilitating teachers' participation in schoolbased health promotion. A qualitative study. Scand J Educ Res 2005; 49(1): 83-109.

[12] World health organisation. The European network of health promoting schools: resource manual. Copenhagen: The WHO Regional Office for Europe 1993.

[13] Rasmussen VB. The European network of health promoting schools - from Iceland to Kyrgyzstan. Promot Educ 2005; 12: 169.

[14] Stewart-Brown S. What is the evidence on school health promotion in improving health or preventing disease and, specifically, what is the effectiveness of the health promoting schools approach? Health Evidence Network report. Copenhagen: The WHO Regional Office for Europe 2006.

[15] Inchley J, Muldoon J, Currie C. Becoming a health promoting school: evaluating the process of effective implementation in Scotland. Health Promot Int 2007; 22(1): 65-71.

[16] Leurs MTW, Bessems K, Schaalma HP, de Vries H. Focus points for school health promotion improvements in Dutch primary schools. Health Educ Res 2007; 22(1): 58-69. 
[17] Anspaugh DJ, Dignan MB, Anspaugh SL. Developing health promotion programs. USA: The McGraw-Hill Companies Inc 2000 .

[18] Green LW, Kreuter MW. Health promotion planning - an educational and ecological approach, $3^{\text {rd }}$ ed. California Mountain View: Mayfield Publishing Company 1999.

[19] World Health Organisation. Ottawa charter for health promotion. WHO Geneva 1986

[20] Fink D, Stoll L. Educational change: easier said than done. In: Hargreaves A, Lieberman A, Fullan M, Hopkins D, Eds. International Handbook of Educational Change. London; Kluwer Academic Publishers 1998; pp. 297-321.

[21] Mukoma W, Flisher AJ. Evaluations of health promoting schools: a review of nine studies. Health Promot Int 2004; 19(3): 357-68.

[22] Harrington R. Best practices in facilitating organizational change in schools. In: Grimes T, Ed. Best practices in school psychology. Washington D.C.; National Association of School Psychologists 1988; pp. 193 - 206

[23] Hargreaves A, Earl L, Moore S, Manning S. Learning to change. Teaching beyond subjects and standards. San Francisco: JosseyBass Inc. 2001.

[24] Imsen G. Lærerens verden [The teacher's world; in Norwegian], $3^{\text {rd }}$ ed. Oslo; Universitetsforlaget 2006.

[25] Harris A. Behind the classroom door: the challenge of organisational and pedagogical change. J Educ Change 2003; 4(4): 369-82.

[26] Senge PM. Schools that learn: getting started. In Senge PM, Cambron-McCabe N, Lucas T, Smith B, Dutton J, Kleiner A, Eds. Schools that learn. A fifth discipline fieldbook for educators, parents, and everyone who cares about education. London: Nicholas Brealey Publishing 2000; pp. 3-58.

[27] Turunen H, Tossavainen K, Jakonen S, Salomäki U, Vertio H. Initial results from the european network of health promoting schools program on development of health education in Finland. J Sch Health 1999; 69(10): 387-91.

[28] Turunen H, Tossavainen K, Vertio H. How can critical incidents be used to describe health promotion in the Finnish European network of health promoting schools? Health Promot Int 2004; 19(4): 41927.

[29] Tjomsland HE, Larsen T, Samdal O, Wold B. Sustaining comprehensive physical activity in elementary school: a case study applying mixed methods. Teach Teach Theor Pract 2010; 16(1): 73-95.

[30] Helle L. Rom for handling? Skoleutvikling i lys av L97 [Room for action. School development in the light of L97; in Norwegian]. Oslo: Tano.Aschehoug 1997.

[31] Kwakman K. Factors affecting teachers' participation in professional learning activities. Teach Teach Educ 2003; 19: 14970 .

[32] Parsons C, Stears D, Thomas C, Thomas L, Holland I. The Implementation of ENHPS in Different National Contexts. Copenhagen: Tecnical Secreteriat of the European Network of Health Promoting Schools 1997.

[33] St Leger L. Reducing the barriers to the expansion of healthpromoting schools by focusing on teachers. Health Educ 2000; 100(2): 81-7.

[34] Hargreaves A, Fink D. Distributed leadership: democracy or delivery? J Educ Adm 2008; 46(2): 229-40

[35] Tjomsland HE, Iversen AC, Wold B. The norwegian network of health promoting schools: a three-year follow-up study of teacher motivation, participation and perceived outcomes. Scand J Educ Res 2009; 53(1): 89-102.

[36] St Leger L. Australian teachers' understanding of the health promoting school concept and the implications for the development of school health. Health Promot Int 1998; 13(3): 223 - 35.
[37] Apostolidou M, Fontana D. Teacher attitudes towards health education in Greek-speaking Cyprus schools. Health Educ 2003; 103: $75-82$

[38] Jensen BB. Environmental and health education viewed from an action-oriented perspective: a case from Denmark. J Curriculum Stud 2004; 36(4): 405-425.

[39] Simovska V. Student participation: a democratic education perspective--experience from the health-promoting schools in Macedonia. Health Educ Res 2004; 19(2): 198-207.

[40] Simovska V. The changing meanings of participation in schoolbased health education and health promotion: the participants voices. Health Educ Res 2007; 22(6): 864-78.

[41] Wentzel KR. Student motivation in middle school: the role of perceived pedagogical caring. J Educ Psychol 1997; 89(3): 411-9.

[42] Mortimore P. The road to improvement. Reflections on school effectiveness. Lisse: Swets and Zeitlinger publishers 1998.

[43] Penlington C, Kington A, Day C. Leadership in improving schools: a qualitative perspective. Sch Leadersh Manag 2008; 28(1): 65-82.

[44] Dusenbury L, Brannigan R, Falco M, Hansen WB. A review of research on fidelity of implementation: implications for drug abuse prevention in school settings. Health Educ Res 2003; 18(2): 237 56

[45] Leithwood K, Harris A, Hopkins D. Seven strong claims about successful school leadership. Sch Leadersh Manag 2008; 28(1): 27 42

[46] Larsen T, Samdal O. Implementing second step: implementation and sustainability. Scand J Educ Res 2008; 52(2): 187-204.

[47] Laurence S, Peterken R, Burns C. Fresh kids: the efficacy of a health promoting schools approach to increasing consumption of fruit and water in Australia. Health Promot Int 2007; 22(3): 218-26.

[48] Datnow A, Murphy J. Leadership lessons from comprehensive school reforms. Thousand Oaks, California: Corwin Press 2003.

[49] Day C, Leithwood K, Sammons P. What we have learned, what we need to know more about. Sch Leadersh Manag 2008; 28(1): 83-96.

[50] Hallinger P. Leading educational change: reflections on the practice of instructional and transformational leadership. Cambr J Educ 2003; 33(3): 329-51.

[51] Hargreaves A, Fink D. Sustaining leadership. Phi Delta Kappan 2003; 84(9): 693-700.

[52] Hargreaves A, Fink D. The seven principles of sustainable leadership. Educ Leadersh 2004; 61(7).

[53] Diamantopoulus A, Winklhofer HM. Index construction with formative indicators: An alternative to scale development. J Market Res 2001; 38(2): 269-277.

[54] Kallestad JH, Olweus D, Alsaker F. School climate reports from norwegian teachers: a methodological and substantive study. Sch Eff Sch Improvem 1998; 9(1): 70-94.

[55] Rivett DH. What is a network? What makes a health promoting schools network? Promot Educ 2005; 12: 168

[56] Parsons C, Stears D. Evaluating health-promoting schools: steps to success. Health Educ 2002; 102(1): 7-15.

[57] Tjomsland HE, Larsen TMB, Viig NG, Wold B. A fourteen year follow-up study of health promoting schools in Norway: Principals' perceptions of conditions influencing sustainability. Open Educ J 2009; 2: 54-64. Retrieved 2010 Jan 18 from website:Avaliable from: http://www.bentham.org/open/toeduj/openaccess $2 . h t m$.

[58] Hansen WB, McNeal RB. Drug education practice: results of an observational study. Health Educ Res 1999; 14(1): 85-97.

[59] St Leger L, Nutbeam D. Research into health promoting schools. J Sch Health 2000; 70(6): 257-9.

[60] Stears D. Profiling the health-promoting school: valuing assets and evaluating the management of change. Health Educ 2000; 100(2): $74-80$.

[61] Schmidt M, Datnow A. Teachers' sense-making about comprehensive school reform: The influence of emotions. Teach Teach Educ 2005; 21: 949-65. 